\title{
On the bilingualism effect in task switching*
}

FRANCESCA M. BRANZI

Neuroscience and Aphasia Research Unit, School of Biological Sciences, University of

Manchester, Manchester, UK

Basque Center on Cognition, Brain and Language (BCBL), San Sebastian, Spain

${ }^{3}$ Center for Brain and Cognition (CBC), Pompeu Fabra University, Barcelona, Spain

MARCO CALABRIA

Center for Brain and Cognition (CBC), Pompeu Fabra University, Barcelona, Spain

MIRIAM GADE

Catholic University of Eichstatt-Ingolstadt, Department of Psychology, General

Psychology, Eichstatt, Germany

\section{LUIS J. FUENTES}

Department of Basic Psychology and Methodology, Faculty of Psychology, University of Murcia, Murcia, Spain

\section{ALBERT COSTA}

Center for Brain and Cognition (CBC), Pompeu Fabra University, Barcelona, Spain

Institució Catalana de Recerca i Estudis Avançats (ICREA), Barcelona, Spain

(Received: June 18, 2015; final revision received: October 23, 2016; accepted: October 27, 2016)

\section{ACKNOWLEDGMENTS}

We are grateful to Dr. Kenneth Paap and Dr. Mireia Hernández for their useful comments on the previous versions of this manuscript. This work was supported by grants from the Spanish Government (PSI2014-54500, PSI2008-01191, PSI201123033, PSI2014-53427-P, Consolider Ingenio 2010 CSD2007-00012), the Catalan Government (Consolidat SGR 2009-1521 and SGR 2014-1210), by one grant from the European Research Council under the European Community's Seventh Framework (FP7/2007-2013 Cooperation grant agreement 613465-AThEME), by one grant from Fundación Séneca (19267/PI/14) and by the Severo Ochoa program grant SEV-2015049. Francesca M. Branzi was supported by a predoctoral fellowship from the Spanish Government (FPU-2009-2013) and by a postdoctoral fellowship from the European Union's Horizon 2020 research and innovation programme, under the Marie Sklodowska-Curie grant agreement No 658341. Marco Calabria was supported by a postdoctoral fellowship from the Spanish Government (Ramón y Cajal Fellowship).

\section{Address for correspondence:}

Francesca M. Branzi

Room 3.19, Neuroscience and Aphasia Research Unit (NARU)

Zochonis Building

University of Manchester,

Brunswick Street

Manchester

M13 9PL

francesca.branzi@gmail.com 


\begin{abstract}
In one task-switching experiment, we compared bilinguals and monolinguals to explore the reliability of the bilingualism effect on the $n$-2 repetition cost. In a second taskswitching experiment, we tested another group of bilinguals and monolinguals and measured both the n-1 shift cost and the $n-2$ repetition cost to test the hypothesis that bilingualism should confer a general greater efficiency of the executive control functioning. According to this hypothesis, we expected a reduced $n-1$ shift cost and an enhanced $n-2$ repetition cost for bilinguals compared to monolinguals. However, we did not observe such results. Our findings suggest that previous results cannot be replicated and that the $n-2$ repetition cost is another index that shows no reliable bilingualism effect. Finally, we observed a negative correlation between the two switch costs among bilinguals only. This finding may suggest that the two groups employ different strategies to cope with interference in task-switching paradigms.
\end{abstract}

Keywords: Bilingualism, executive control, task switching, n-2 repetition cost 


\section{Introduction}

The issue of whether bilingualism affects an individual's executive control (EC) functioning has recently been the subject of debate. Despite some studies showing bilingualism's impact on the EC system (e.g., Costa, Hernández \& Sebastián-Gallés, 2008; Bialystok, Craik, Green \& Gollan, 2009; Costa, Hernández, Costa-Faidella \& Sebastián-Gallés, 2009; Abutalebi, Della Rosa, Green, Hernández, Scifo, Keim, Cappa \& Costa, 2012; Barac \& Bialystok, 2012; Gold, Kim, Johnson, Kryscio \& Smith, 2013; Pelham \& Abrams, 2014; Houtzager, Lowie, Sprenger \& de Bot, 2015; Vega-Mendoza, West, Sorace \& Bak, 2015; Verreyt, Woumans, Vandelanotte, Szmalec \& Duyck, 2016; Wiseheart, Viswanathan \& Bialystok, 2016), other findings have challenged these observations, and questions have been raised about the robustness and reliability of the bilingualism effect on EC (e.g., Kousaie \& Phillips, 2012a, 2012b; Paap \& Greenberg, 2013; Prior \& Gollan, 2013; Duñabeitia, Hernández, Antón, Macizo, Estévez, Fuentes \& Carreiras, 2014; Kousaie, Sheppard, Lemieux, Monetta \& Taler, 2014; Mor, Yitzhaki-Amsalem \& Prior, 2015; Paap, Johnson \& Sawi, 2014; Paap \& Sawi, 2014; de Bruin, Bak \& Della Sala, 2015; von Bastian, Souza \& Gade, 2016). Indeed, failures to replicate seminal results have divided the researchers in the field; while some have attributed these inconsistencies to methodological factors (see Bak, 2015; Valian, 2015; Yang, Hartanto \& Yang, 2016), others have even discredited the existence of the phenomenon per se (e.g., Paap, Johnson \& Sawi, 2015).

In an attempt to deal with more sceptical views, recent research efforts have been dedicated to specifying the cognitive processes affected by bilingualism by testing large samples of participants on different EC tasks measuring various cognitive processes. In doing so, many recent studies have provided direct and conceptual replications ${ }^{1}$ of previous experiments in which bilingualism effects were observed. In this context, it has 
become increasingly evident that many cognitive indexes (e.g., conflict effect, n-1 shift cost, etc.) that are generally used to measure EC among bilinguals and monolinguals do not reliably show bilingualism effects. Although a possible reason is that the 'phenomenon' itself (i.e., bilingualism effect on EC) does not exist (e.g., Paap et al., 2015), some cognitive indexes still need to be explored for reliability before reaching a definitive conclusion.

One of the goals of the present study is to focus on one index of EC functioning that should be explored better with respect to bilingualism, such as the n- 2 repetition cost in task switching (Mayr \& Keele, 2000; Prior, 2012). This cost refers to the observation that when switching among three tasks, switching back to a recently performed task (ABA) is harder than switching to a new task (CBA), as indicated by longer response times (RTs) and the increased number of errors. This effect is often interpreted as reflecting residual inhibition, which needs to be overcome and hampers the reactivation of the currently relevant task (e.g., Mayr \& Keele, 2000).

Recent evidence suggests that inhibition that is measured through the $\mathrm{n}-2$ repetition cost cannot be generalised from bilingual language control to domain-general EC (Babcock \& Vallesi, 2015; Branzi, Calabria, Boscarino \& Costa, 2016). Given these results, researchers should not expect any effect of bilingualism on this index of inhibitory control. In other words, researchers should predict that they will likely observe similar $\mathrm{n}-2$ repetition costs when comparing bilinguals and monolinguals.

However, the issue is quite controversial. In a previous study, Prior (2012) found bilinguals showing larger $n-2$ repetition costs than monolinguals. To explain this result, the author argued that life-long language control experience with inhibitory control made bilingual speakers more efficient in applying inhibitory control processes than monolinguals and, consequently, more prone to show larger costs related to inhibition ${ }^{2}$ 
(i.e., n-2 repetition costs). This finding is especially interesting because it shows that under proper experimental conditions, more efficient EC functioning may lead to poorer performance (see also Hernández, Costa \& Humphreys, 2012 for a similar argument). Since this result has not yet been replicated and, to some extent, it contrasts with recent findings (e.g., Babcock \& Vallesi, 2015; Branzi et al., 2016), the present study aims to assess its reliability.

Another interesting issue explored in the task-switching literature is how the finding about larger n-2 repetition costs for bilinguals (Prior, 2012) is reconcilable with the result about reduced n-1 shift costs for bilinguals (Prior \& MacWhinney, 2010).

According to Prior (2012), the bilingual advantage in n-1 shift costs (e.g., Prior \& MacWhinney, 2010) and the bilingual 'disadvantage' in n-2 repetition costs may arise because bilinguals are more efficient in applying the dominant strategy as determined by experimental conditions ${ }^{3}$, might this be the reliance on task activation (e.g., when repetition trials are present in the task) or on task inhibition (e.g., when only switch trials are present) or on both processes. However, an alternative hypothesis explains the same pattern of switch costs among bilinguals, which refers to their enhanced abilities of inhibitory control. In fact, if bilinguals are better inhibitors than monolinguals, they may apply a stronger inhibition of the just executed task. This would result in a bilingual advantage in $n-1$ shift costs and at the same time, in a 'disadvantage' in $n-2$ repetition costs.

Although the reported switch costs patterns may originate from either a bilingualism effect on inhibition or a generalised cognitive advantage, both these hypotheses predict a striking pattern of results. First, they predict an interaction between the language status and the magnitude of the different switch costs. In other words, in the same experiment, one should expect to observe larger n-1 shift costs for monolinguals and 
larger n-2 repetition costs for bilinguals. Second, if both n-1 shift costs and n-2 repetition costs originate from the same mechanism (e.g., inhibition), one should expect to find a negative correlation between the magnitude of $n-1$ shift costs and that of $n-2$ repetition costs, likely irrespective of the participants' language status. In other words, based on the assumption that inhibition (measured as $n-2$ repetition costs) contributes to n-1 shift costs (Mayr \& Keele, 2000), the better an individual's inhibitory functioning is, the smaller the $n-1$ shift cost and the larger the $n-2$ repetition cost should be. This assumption was recently tested in one study in our laboratory (Branzi et al., 2016). Actually, we revealed a negative significant correlation between the two costs in a group of bilinguals. However, it remains an empirical question whether the same results would be observed among monolinguals.

The present study aims at filling this gap by testing these two predictions. Furthermore, considering our assessment of $n-2$ repetition costs and n-1 shift costs within the same experimental design, we can draw a direct link between the differences for monolinguals and bilinguals that have been observed to date.

\subsection{The present study}

To summarise, we conducted two task-switching experiments. In Experiment 1, we aimed at providing the first conceptual replication of a cognitive index in task switching related to bilingualism, that is, the $\mathrm{n}-2$ repetition cost. Hence, we performed an experiment similar to that of Prior (2012) in which we tested a group of 90 participants (40 Catalan-Spanish highly proficient bilinguals and 50 Spanish monolinguals) in a task-switching paradigm, where they had to sort a given target according to three possible perceptual tasks indicated by valid cues (i.e., symbols surrounding a frame containing the stimulus). The trials' sequence was set to make it possible to assess the 
n-2 repetition cost (ABA vs. CBA task sequences). We hypothesised that if the $n-2$ repetition cost would be a reliable index that could be used to argue about the differences in EC functioning between bilinguals and monolinguals, we should find the same results as those of Prior (2012).

In Experiment 2, we introduced task repetitions to measure both the n-2 repetition costs and the n-1 shift costs. In this way, we were able to assess whether bilinguals would show larger $n-2$ repetition costs and smaller $n-1$ shift costs than monolinguals in the same task-switching experiment. We conducted a second experiment with 205 participants (100 Catalan-Spanish highly proficient bilinguals and 105 Spanish monolinguals), in which both the $n-1$ shift costs and the $n-2$ repetition costs were assessed at the same time. The participants were asked to perform the same experiment as Experiment 1, except that repetition trials were included in the task. Hence, the trials' sequence was set in such a way that we could assess both the $n-1$ shift costs (CBA vs. CAA task sequences) and the $n-2$ repetition costs (ABA vs. CBA task sequences). Importantly, to explore the relationship between the n-1 shift costs and the n-2 repetition costs, we carried out a correlation analysis between them for all the participants, as well as for bilinguals and monolinguals separately.

\section{Experiment 1: task switching without repetitions}

\subsection{Materials and methods}

\section{Participants}

Ninety participants (40 Catalan-Spanish highly proficient bilinguals and 50 Spanish monolinguals) were tested in Experiment 1. Five bilingual and nine monolingual participants were eliminated from the individual dataset for the following reasons: 1) age over the established range (i.e., participants older than 30), 2) number of errors that 
were three standard deviations (SDs) above the group mean and 3) inappropriate language status (e.g., some participants in the monolingual group were bilinguals). Therefore, the analyses reported below refer to 35 bilinguals ( 21 females; mean age $=$ 22 years, $\mathrm{SD}= \pm 2$ ) and 41 monolinguals ( 34 females; mean age $=22$ years, $\mathrm{SD}= \pm 4$ ). All the participants were right-handed university students and had normal or correctedto-normal vision. ${ }^{4}$ Information about the languages and the self-assessed proficiency of the bilinguals and the monolinguals are reported in Table 1. Furthermore, Table 5 presents the scores relative to the frequency of language switching by bilinguals, which were assessed by administering the bilingual switching questionnaire (BSWQ) (Rodriguez-Fornells, Krämer, Lorenzo-Seva, Festman \& Münte, 2012). Finally, a detailed description of the bilingual and the monolingual samples is reported in Appendix.

$<$ Please insert Table 1 around here.>

Raven's Advanced Progressive Matrices and scores relative to socio-economic status (SES)

The bilinguals and the monolinguals completed Superior Scale I of Raven's Advanced Progressive Matrices (Raven, Raven \& Court, 1998) that measures non-verbal intelligence. The test consists of 12 puzzles with a missing piece. The participants were asked to select one piece among eight possibilities to complete the puzzle. The test lasted approximately 10 minutes. Both groups had comparable scores $[t(74)=1.063, p$ $=0.291]$.

We also calculated SES scores based on parental education (years) and total monthly family income (the scores ranged from 1 to 5 , depending on the family's total 
income, e.g., $<€ 800=1, € 800-1200=2$, €1201-1800 = 3, etc.). Regarding parental education, bilinguals (mean years $=12.88, \mathrm{SD}= \pm 2.4$ ) and monolinguals $($ mean years $=$ $13.31, \mathrm{SD}= \pm 2.1)$ were comparable $[t(74)=0.825, p=0.412]$. In terms of total family income, bilinguals (mean score $=3.6, \mathrm{SD}= \pm 1.3$ ) and monolinguals (mean score $=3.3$, $\mathrm{SD}= \pm 1.4)$ were comparable $[t(74)=-0.961, p=0.34]$.

\section{Materials}

The participants were presented with three-dimensional stimuli and were required to switch among three perceptual classification tasks. Similar to previous studies (Philipp \& Koch, 2006; Branzi et al., 2016), the tasks required sorting stimuli by "type" (A vs. 4), "size" (big vs. small) and "colour" (red vs. blue). The stimuli were presented one at a time on a white background at the centre of the screen. Each task was indicated by four cue signs surrounding the stimulus. The cues were paragraph symbols for the type task, small yellow squares for the colour task, and up-down pointing arrows for the size task. The responses were given manually on an external keyboard with three response keys for each hand. Similar to our previous study (Branzi et al., 2016), we adopted this setting to avoid response overlapping across tasks. Hence, three keys were used to respond to "A", "big" and "red" and three other keys were used to respond to "4", "small" and "blue".

\section{Procedure}

In the beginning, the participants received written and oral instructions for the experiment. Next, they took part in the experiment in a single session of approximately 45 minutes. The instructions emphasised speed and accuracy. We informed the participants about the tasks and the response keys (the response keys on the keyboard 
were labelled) but did not mention the presence or absence of repetitions. Before being tested in the experiment, all the participants were trained in a practice session to familiarise themselves with the task and to learn stimulus-response (S-R) mappings appropriately.

The experiment consisted of six blocks, each with 108 trials. The response-stimulus interval (RSI) was maintained constant $(1100 \mathrm{~ms})$, as well as the cue-stimulus interval (CSI) (100 ms).

In this experiment, the $\mathrm{ABA}$ (or $n$-2 repetition) and the CBA (or $n$ - 2 switch) task sequences occurred with a probability of $50 \%$ each. We refer to A, B and C to indicate each task (i.e., type, size and colour), which occurred in the experiment with an equal probability. A trial started with a blank screen, followed by the cue (i.e., a blank frame surrounded by four cue signs), and after $100 \mathrm{~ms}$ (CSI), the stimulus was presented in the middle of the blank frame, simultaneously with an acoustic tone. The stimulus and the cue remained on the screen until the response was given (or with a maximum delay of $7000 \mathrm{~ms}$ ). The next cue followed after $1000 \mathrm{~ms}$, leading to an RSI of $1100 \mathrm{~ms}$. At the end of each block, the participants were allowed to take a break and received a feedback relative to their performance, given as the percentage of correct responses.

\section{Data analysis and results}

Each trial was assigned to one of the two conditions (i.e., CBA or n-2 switch, $\mathrm{ABA}$ or $n$ 2 repetition), depending on the nature of the two preceding trials (the $n-1$ and the $n-2$ trials). For example, considering the sequence $\mathrm{CBA}$, where $\mathrm{A}$ is trial $n, \mathrm{~A}$ is preceded by $n-1$ trial $\mathrm{B}$ and $n-2$ trial $\mathrm{C}$. In this case, trial $\mathrm{A}(n)$ is assigned to the condition CBA or $n$ 2 switch, given that trial $n-1$ and trial $n-2$ are both different from A. On the other hand, in the ABA sequence, $n$ trial $\mathrm{A}$ is preceded by $n-1$ trial $\mathrm{B}$ and $n-2$ trial $\mathrm{A}$. In this case, $n$ 
trial $\mathrm{A}$ is assigned to the condition $n-2$ repetition, given that the $\mathrm{n}-2$ trial and the $n$ trial require to performing the same task (i.e., A). The first two trials of each block were excluded from the analysis because they could not be classified as either ' $n$ - 2 switch' or ' $n$-2 repetition'.

The RTs exceeding three SDs above or below a participant's mean were excluded from the analyses. Then, every error and the two trials following an error were also discarded, leading to a data loss of $10 \%(\mathrm{SD}= \pm 6)$ for bilinguals and $9 \%(\mathrm{SD}= \pm 5)$ for monolinguals.

First, we analysed RTs and error rates for the two types of sequences, that is, ABA (or $n$-2 repetition) and CBA (or $n$-2 switch), to explore potential differences in the overall speed and accuracy between bilinguals and monolinguals. Hence, we ran two repeated-measures ANOVAs (one for RTs and the other for error rates) with types of sequence (ABA or $n-2$ repetition and $\mathrm{CBA}$ or $n-2$ switch) as a within-subject factor and group (bilinguals and monolinguals) as a between-subject factor.

Furthermore, when the interaction between types of sequence and group was significant, in a successive analysis, we also compared the magnitude of the $n-2$ repetition cost between bilinguals and monolinguals. The $\mathrm{n}-2$ repetition cost was calculated by subtracting the RTs of the CBA task sequences from those of the ABA task sequences.

Mean RTs, error rates and magnitudes of the $n-2$ repetition cost in the two groups are reported in Table 2.

$<$ Please insert Table 2 around here> 


\section{$R T s$ and error rates}

For RTs, ANOVA results revealed a significant main effect of types of sequence [F (1, $\left.74)=126.458, p<0.001, \eta p^{2}=0.631\right]$, indicating that the ABA conditions $(1167 \mathrm{~ms})$ were significantly slower than the CBA conditions $(1112 \mathrm{~ms})$. The main effect of group was significant $\left[\mathrm{F}(1,74)=6.782, p=0.011, \eta p^{2}=0.084\right]$, suggesting that bilinguals were overall faster than monolinguals (bilinguals $=1062 \mathrm{~ms}$; monolinguals $=1217 \mathrm{~ms}$ ). Finally, the types of sequence $X$ group interaction was not significant $[F(1,74)=1.337$, $\left.p=0.251, \eta \mathrm{p}^{2}=0.018\right]$. This result showed that the magnitude of the $\mathrm{n}-2$ repetition cost was not different between the groups (bilinguals $=50 \mathrm{~ms}$; monolinguals $=62 \mathrm{~ms}$ ).

For error rates, the main effect of types of sequence was not significant $[\mathrm{F}(1,74)=$ 1.060, $\left.p=0.306, \eta p^{2}=0.014\right]$, indicating that the ABA conditions $(3.3 \%)$ and the CBA conditions $(3.1 \%)$ elicited the same amount of errors. No significant difference in error rates between monolinguals $(3 \%)$ and bilinguals $(3.4 \%)$ was found [ group: $\mathrm{F}(1,74)=$

$\left.0.435, p=0.512, \eta p^{2}=0.006\right]$. The interaction between types of sequence and group showed a trend towards significance $\left[\mathrm{F}(1,74)=3.221, p=0.077, \eta p^{2}=0.042\right]$. A closer look at the data revealed that this interaction was due to the bilinguals' similar error rates in the $\mathrm{CBA}(3.4 \%)$ and the $\mathrm{ABA}$ conditions (3.3\%). In contrast, monolinguals made more errors in the ABA conditions $(3.3 \%)$ than in the CBA conditions (2.8\%) (see Table 2).

The results presented above suggest that the magnitude of the $n-2$ repetition cost in RTs is not modulated by bilingualism. However, bilinguals appear to be faster than monolinguals across all conditions (see Costa et al., 2008).

To test the bilingualism effect on both the $n-2$ repetition costs and the $n-1$ shift costs in the same task switching, we ran a second experiment, in which we tested bilingual and monolingual participants. 


\section{Experiment 2: task switching with repetitions}

\subsection{Materials and methods}

\section{Participants}

One hundred highly proficient Catalan-Spanish bilinguals and 105 Spanish monolinguals took part in Experiment 2 with task repetitions. Nine bilinguals and four monolinguals were eliminated from the individual dataset due to the same issues reported in Experiment 1. Therefore, the analyses reported below refer to 91 bilinguals (62 females; mean age $=22$ years, $\mathrm{SD}= \pm 2)$ and 101 monolinguals $(90$ females; mean age $=21$ years, $\mathrm{SD}= \pm 3$ ). All the participants were right-handed university students and had normal or corrected-to-normal vision. ${ }^{5}$ Information about the languages and the self-assessed proficiency of bilinguals and monolinguals are reported in Table 3 . Furthermore, Table 5 presents the scores relative to the frequency of language switching by bilinguals, which were assessed by administering the BSWQ (RodriguezFornells et al., 2012). Finally, a detailed description of the bilingual and the monolingual samples is reported in Appendix.

<Please insert Tables 3 and 5 around here.>

Raven's Advanced Progressive Matrices and scores relative to SES

The bilinguals and the monolinguals completed Superior Scale I of Raven's Advanced Progressive Matrices (Raven et al., 1998). Both groups obtained comparable scores $[t$ $(190)=-0.719, p=0.473]$.

We calculated the SES scores based on parental education (years) and total family monthly income, similar to Experiment 1 . With respect to parental education, bilinguals 
(mean years $=13, \mathrm{SD}= \pm 2.5)$ and monolinguals (mean years $=12.6, \mathrm{SD}= \pm 3.1$ ) were comparable $[t(190)=-1.181, p=0.239]$. Regarding total family income, bilinguals (mean score $=3.4, \mathrm{SD}= \pm 1.4$ ) and monolinguals (mean score $=3.1, \mathrm{SD}= \pm 1.3$ ) were comparable $[t(190)=-1.355, p=0.177]$.

\section{Materials}

The materials used in Experiment 1 were also used in Experiment 2.

\section{Procedure}

Experiment 2 adopted the same procedure as that of Experiment 1, except that repetition trials (i.e., CAA) were present. We opted for the following frequencies of task triplets as explained below. Both the $\mathrm{ABA}$ (or $n-2$ repetition) and the $\mathrm{CBA}$ (or $n$ - 2 switch) task sequences occurred with a $39 \%$ probability, and the CAA (or $n-1$ repetition) task sequences occurred with an $11 \%$ probability (note that the sum of probabilities was lower than $100 \%$ because all trials following repetitions were not analysed).

Some studies have suggested that the magnitude of the $n-2$ repetition cost may be hindered by the presence of task repetitions (e.g., Philipp \& Koch, 2006). This appears to be true when repetition trials (i.e., CAA) are as frequent as the $n-2$ switch (i.e., CBA) and the $n$-2 repetition (i.e., ABA) trials (see Experiment 1 in Philipp \& Koch, 2006). However, when the occurrence of repetitions is notably reduced ${ }^{6}$ compared to that of the other two conditions, the size of the $\mathrm{n}-2$ repetition cost is not dramatically affected (see Experiment 2 in Philipp \& Koch, 2006). Hence, given that we aimed to assess the two costs in the same experiment, we decided to introduce fewer repetitions (e.g., CAA) compared to the other two conditions. 


\section{Data analysis and results}

Each trial was assigned to one of the three conditions (CBA or $n-2$ switch, ABA or $n-2$ repetition and CAA or $n-1$ repetition), depending on the nature of the two preceding trials ( $n-1$ and $n-2$ trials). The first two trials of each block were excluded from the analysis, as well as the trials after repetitions (i.e., CCA).

The RTs exceeding three SDs above or below a participant's mean were excluded from the analyses. Every error and the two trials following an error were also discarded, leading to a data loss of $9 \%(\mathrm{SD}= \pm 6)$ for bilinguals and $10 \%(\mathrm{SD}= \pm 6)$ for monolinguals.

First, we analysed RTs and error rates for the three types of sequences - ABA ( $n-2$ repetition), CBA ( $n-2$ switch) and CAA ( $n-1$ repetition) - to reveal potential differences in the overall speed and error rates between the two groups. To do so, we performed two repeated-measures ANOVAs (one for RTs and the other for error rates), with types of sequence (ABA or $n-2$ repetition, $\mathrm{CBA}$ or $n-2$ switch and CAA or $n-1$ repetition) as a within-subject factor and group (bilinguals and monolinguals) as a between-subject factor.

Furthermore, when the interaction between types of sequence and group was significant, we compared the magnitude of the $n-2$ repetition cost and the $n-1$ shift cost between bilinguals and monolinguals in a successive analysis. Hence, we performed an ANOVA by considering types of cost ( $\mathrm{n}-1$ shift cost and $\mathrm{n}-2$ repetition cost) as a withinsubject factor and group (bilinguals and monolinguals) as a between-subject factor. Similar to Experiment 1, the n-2 repetition cost was calculated by subtracting the RTs of the $\mathrm{CBA}$ task sequences from those of the $\mathrm{ABA}$ task sequences. The $\mathrm{n}-1$ shift cost was calculated by subtracting the RTs of the CAA task sequences from those of the CBA task sequences. 
Importantly, we were interested in exploring the relationship between the n- 1 shift costs and the $\mathrm{n}-2$ repetition costs. Therefore, we performed a correlation analysis between the magnitudes of these two costs across all participants, as well as separately for the two groups of participants.

Mean RTs, error rates and magnitudes of the switch costs are reported in Table 4. The correlation analyses relative to the $n-1$ shift and the $n-2$ repetition costs are illustrated in Figures 1, 2 and 3.

$<$ Please insert Table 4 and Figures 1, 2 and 3 here>

\section{$R T$ s and error rates}

For RTs, the ANOVA results revealed a significant main effect of types of sequence [F $\left.(2,380)=132.123, p<0.001, \eta p^{2}=0.410\right]$. Post-hoc tests showed that each task sequence was different from one another (all $p_{s}<0.001$ ), that is, the CAA conditions were the fastest $(1005 \mathrm{~ms})$, and the ABA conditions were the slowest $(1101 \mathrm{~ms})$, with the CBA conditions in the middle $(1052 \mathrm{~ms})$. The main effect of group was not significant $\left[\mathrm{F}(1,190)=1.704, p=0.193, \eta \mathrm{p}^{2}=0.009\right]$, suggesting similar overall RTs in the two groups (bilinguals $=1035 \mathrm{~ms}$; monolinguals $=1070 \mathrm{~ms}$ ). Moreover, the types of sequence $X$ group interaction was also not significant $[\mathrm{F}(2,380)=0.611, p=0.543$, $\eta \mathrm{p}^{2}=0.003$ ], suggesting that the magnitudes of the costs were the same in both groups $(\mathrm{n}-1$ shift cost: bilinguals $=50 \mathrm{~ms} ;$ monolinguals $=43 \mathrm{~ms} ; \mathrm{n}-2$ repetition cost: bilinguals $=43 \mathrm{~ms}$; monolinguals $=56 \mathrm{~ms})$.

For error rates, the main effect of types of sequence was significant $[\mathrm{F}(2,380)=$ $10.536, p<0.001, \eta \mathrm{p}^{2}=0.053$ ], indicating that the participants were more error prone in the ABA conditions (3.6\%) than in the CAA conditions $(2.9 \%)$ or in the CBA 
conditions $(3.2 \%)$ (all $\left.p_{s} \leq 0.001\right)$. However, the CAA and the CBA conditions did not differ $(p=0.351)$. No significant difference in error rates between bilinguals $(3 \%)$ and monolinguals $(3.4 \%)$ was found [group: $\mathrm{F}(1,190)=1.631, p=0.203, \eta p^{2}=0.009$ ]; the interaction between types of sequence and group was not significant, either $[\mathrm{F}(2,380)=$ 2.322, $\left.p=0.100, \eta p^{2}=0.012\right]$. These results indicated that the two costs were similar in both groups $(\mathrm{n}-1$ shift cost: bilinguals $=0.7 \%$; monolinguals $=0 \% ; \mathrm{n}-2$ repetition cost: bilinguals $=0.2 \%$; monolinguals $=0.6 \%$.

\section{Correlations between the $n-1$ shift cost and the $n-2$ repetition cost}

We proposed that if $n-1$ shift costs and $n-2$ repetition costs originate from the same cognitive mechanism, we should expect to find a negative correlation between the magnitude of n-1 shift costs and that of $n-2$ repetition costs across all participants. Before performing correlation analyses, we examined the distribution of the switch costs values for each group and excluded outliers from our data (Tukey's test). The outlier free data set originating from the application of this procedure allowed us to correlate the two costs for 87 bilinguals and 96 monolinguals. Importantly, the results relative to the switch costs, as previously revealed (see above), remained unchanged after the elimination of the outliers. ${ }^{7}$

To explore whether the n- 1 shift cost and the $n-2$ repetition cost were related, we performed a correlation analysis (Pearson's coefficient) for the two costs across all participants. To assess whether the phenomenon was similarly present for bilinguals and monolinguals, we also conducted a correlation analysis for the two groups separately. Interestingly, we found a significant negative correlation between the magnitudes of the $\mathrm{n}-1$ shift costs and the $\mathrm{n}-2$ repetition costs across all participants $[r=-0.181, p=0.014]$. However, when the two groups were taken apart, this correlation was significant for the 
bilingual group $[r=-0.297, p=0.005]$ but not for the monolingual group $[r=-0.054, p$ $=0.601]$ (see Figures 1, 2 and 3).

Furthermore, we calculated the significance of the difference between the correlation coefficients obtained among bilinguals and monolinguals (i.e., $r$-bil and $r$ mono). We did so by using the Fisher r-to-z transformation to convert each correlation coefficient into a z-score. Then, by making use of the sample size employed to obtain each coefficient, we compared the z-scores (see the formula in Cohen \& Cohen, 1983). The results revealed that $r$-bil was significantly smaller than $r$-mono $(\mathrm{z}=-1.68, p=$ $0.047)$.

Correlations between the magnitudes of the switch costs and the language-switching scores $(B S W Q)$

A certain amount of scientific work has recently emphasised the importance of exploring the relationship between different aspects of linguistic experience and EC (e.g., Prior \& Gollan, 2011; Verreyt, Woumans, Vandelanotte, Szmalec \& Duyck, 2015; Hartanto \& Yang, 2016; Yang et al., 2016). Hence, this analysis aimed to explore the variability in EC responses as a function of a detailed characterisation of individual differences in language switching, measured through the BSWQ (Rodriguez-Fornells et al., 2012).

Hence, for Experiments 1 and 2 separately, we performed a correlation analysis (Pearson's coefficient) between the switch costs ( $\mathrm{n}-1$ shift and $\mathrm{n}-2$ repetition costs) and the BSWQ scores. Precisely, the switch costs were correlated with (a) first-language (L1) switching tendencies (the tendency to switch from the second language [L2] to L1), (b) second-language switching tendencies (the tendency to switch from L1 to L2), 
(c) contextual switch (CS), (the frequency of switches in particular contexts) and (d) unintended switch (US) (the frequency of unconscious language switches).

The results are reported in Table 6. Interestingly, although we did not find any significant correlation in Experiment 1, we did find a significant correlation between the n-2 repetition cost and the scores relative to L2-switching tendencies in Experiment 2.

<Please insert Table 6 around here>

\section{General discussion}

The present study aimed to explore two main issues related to the effects of bilingualism in task switching.

First, we intended to provide a conceptual replication of the bilingualism effect on the $n-2$ repetition cost found by Prior (2012). Importantly, this cognitive index (i.e., the n-2 repetition cost) has been considered particularly relevant to determine how the experience of bilingualism shapes an individual's EC system. In fact, it has been suggested that the $n-2$ repetition cost captures the efficiency of an EC mechanism that is crucial for bilingual language control, that is, inhibitory control (e.g., Mayr \& Keele, 2000; Gade, Schuch, Druey \& Koch, 2014). Hence, following Prior's (2012) argument, the bilinguals' better inhibitory system (due to their daily experience with inhibitory control during language processing) should have resulted in increased n-2 repetition costs compared to monolinguals. The results of Experiment 1 are clearly at odds with this prediction since we found that bilinguals' $n-2$ repetition costs were similar to those of monolinguals. Interestingly, we obtained the same results in Experiment 2. Hence, 
across more than 200 participants, we did not find any effect of bilingualism on the n-2 repetition cost.

Despite differences between our study and that of Prior (2012), such as the number of tested participants and the bilinguals' languages, the two studies are likely comparable in their main properties. Hence, the available evidence, along with other recent results (Babcock \& Vallesi, 2015; Branzi et al., 2016), casts some doubt on the robustness and the reliability of the phenomenon itself.

It is also noteworthy that in our study, bilinguals and monolinguals showed similar n-1 shift costs (Experiment 2). This result is consistent with that of Hernández, Martin, Barceló \& Costa's (2013) study, in which they tested a large number of participants (145 bilinguals and 147 monolinguals) performing different versions of the taskswitching paradigm. Interestingly, Hernández et al. (2013) failed to observe any modulation of the $n-1$ shift cost due to bilingualism. If we add the current set of results to such a study, along with other recent evidence (e.g., Paap \& Greenberg, 2013; Paap \& Sawi, 2014; de Bruin et al., 2015; von Bastian et al., 2016), it appears that the bilingualism advantage on the $\mathrm{n}-1$ shift cost is rather elusive and very limited in scope, if it indeed exists.

Overall, on one hand, the results concerning the magnitudes (RTs) of the two costs suggest a limited impact of bilingualism on some aspects of the EC system and raise concerns about the generalisability of previous observations (see also Paap \& Greenberg, 2013; Paap et al., 2015). On the other hand, these findings confirm those of recent studies that revealed a lack of overlap between the linguistic and the nonlinguistic n-1 shift costs and n-2 repetition costs (Calabria, Hernández, Branzi \& Costa, 2012; Prior \& Gollan, 2013; Babcock \& Vallesi, 2015; Calabria, Branzi, Marne, 
Hernández \& Costa, 2015; Cattaneo, Calabria, Marne, Gironell, Abutalebi \& Costa, 2015; Branzi et al., 2016).

Along the same lines, even if we reported an overall faster performance of bilinguals compared to monolinguals in Experiment 1, we failed to reveal any significant difference between the groups in Experiment 2. It is difficult to decide whether we should consider these results in contrast to or in accord with the hypothesis of a bilingual advantage in monitoring control (e.g., Costa et al., 2008, 2009). Nevertheless, it is important to acknowledge that this hypothesis has been strongly questioned in recent years. For instance, from 2011 to 2014, bilingual advantages in global RTs had been reported only in $13 \%$ of the studies using conflict-resolution tasks (see Paap et al., 2015). Failures in revealing such bilingual advantages seem to be especially evident in those studies that should be powerful enough to detect small effects due to the large sample sizes employed (e.g., Hernández et al., 2013; Paap \& Greenberg, 2013; Antón, Duñabeitia, Estévez, Hernández, Castillo, Fuentes, Davidson \& Carreiras, 2014; Paap et al., 2014; von Bastian et al., 2016). Taking into account the current literature, our findings do not provide strong support for the hypothesis of a bilingual advantage in monitoring control.

Regarding the second issue investigated in this study, we also hypothesised a negative correlation between the $n-1$ shift cost and the $n-2$ repetition cost across all participants, to the extent to which these two costs would reflect the efficiency of the same control mechanism (e.g., inhibitory control). However, we found such a correlation in the bilingual group only.

A conceivable explanation for this finding is that among bilinguals, the deployment of the same control mechanism lies behind the two costs. One possibility is that this mechanism is inhibitory control applied to the n-1 task. To recall, a strong inhibition of 
the just executed task would result in smaller n- 1 shift costs and larger n-2 repetition costs. A low level of inhibitory control over the n-1 task would lead to the opposite pattern. Interestingly, the negative correlation found among bilinguals was accompanied by similar magnitudes of switch costs. Hence, it is possible that some of the bilinguals might have applied high levels of inhibition to the n-1 tasks, leading to small n-1 shift costs and large n-2 repetition costs. Others might have applied low levels of inhibition to the $n-1$ tasks, resulting in large $n-1$ shift costs and small $n-2$ repetition costs.

Regardless of the merits of this explanation, it is unclear why monolinguals did not show this correlation. Indeed, both bilinguals and monolinguals showed similar magnitudes of the two switch costs, suggesting that they were similarly engaged in $n-2$ repetition and n-1 shift costs. One possibility is that monolinguals might have tended to apply a similar degree of inhibition to $\mathrm{n}-1$ tasks, and this sort of clustering around a common inhibition level would not have allowed for a negative correlation between the costs to emerge.

Another tentative explanation is that differential findings relative to the correlation between the two costs might reflect qualitative differences related to the experience with bilingual language control. We propose that the presence of a correlation likely suggests the same mechanism behind the two costs (see also Branzi et al., 2016). The lack of such a correlation might thus indicate that the $n-1$ shift cost and the $n-2$ repetition cost measure, at least in part, different mechanisms. In this regard, it might be that bilinguals employ just one mechanism (which might be inhibitory control) during task switching. Interestingly, we also recently found a negative correlation between the two costs during language switching, suggesting that bilinguals might also apply the same 'strategy' when switching between languages (see Branzi et al., 2016). In contrast, monolinguals might employ other mechanisms besides inhibitory control, which would 
affect the n-1 shift cost in task switching (in fact, the n-2 repetition cost would specifically measure inhibitory control). Therefore, the lack of correlation that we observed among monolinguals might be due to the variability added by these other processes that were measured through the $\mathrm{n}-1$ shift cost.

Taken together, results from this and our previous study (Branzi et al., 2016) might suggest qualitatively different strategies between bilinguals and monolinguals during task switching. Consistent with this interpretation, Garbin, Sanjuan, Forn, Bustamante, Rodriguez-Pujadas, Belloch, Hernández, Costa \& Ávila (2010) showed that when performing non-linguistic cognitive tasks, bilinguals used different brain areas compared to monolinguals. Crucially, these brain areas were those generally involved in bilingual language control, leading to the hypothesis that the qualitative difference in EC between bilinguals and monolinguals might be related to different linguistic experiences.

Nonetheless, we are strongly convinced that additional empirical evidence is needed to provide a clear theoretical explanation for these findings.

\section{Conclusion}

The present study provides two main contributions. First, it shows that bilingualism does not seem to affect the magnitude of the $n-2$ repetition cost in RTs. Consistent with previous findings (e.g., Branzi et al., 2016), this result suggests that the $\mathrm{n}-2$ repetition cost may not be a reliable index to support the hypothesis of a bilingualism effect on EC. This study has also failed to reveal any effect of bilingualism on the n-1 shift cost. This finding, along with previous ones (e.g., Hernández et al., 2013), suggests that future research on the effects of bilingualism should not be confined to the effects of the magnitude of the switch costs. 
Second, this study reveals qualitative differences between bilinguals and monolinguals relative to the negative correlation between the magnitudes of switch costs. This is a rather new finding and may suggest that bilinguals and monolinguals employ different cognitive strategies to cope with interference in task switching. Future research is needed to assess the reliability of this result and whether it is relatable to specific aspects of bilingualism. 


\section{References}

Abutalebi, J., Della Rosa, P.A., Green, D.W., Hernández, M., Scifo P., Keim, R., Cappa, S. F., \& Costa, A. (2012). Bilingualism tunes the anterior cingulate cortex for conflict monitoring. Cerebral Cortex, 22(9), 2076-2086.

Antón, E., Duñabeitia, J. A., Estévez, A., Hernández, J. A., Castillo, A., Fuentes, L. J., Davidson, D. J., \& Carreiras, M. (2014). Is there a bilingual advantage in the ANT task? Evidence from children. Frontiers in Psychology, 5.

Babcock, L., \& Vallesi, A. (2015). Language control is not a one-size-fits-all languages process: Evidence from simultaneous interpretation students and the $\mathrm{n}-2$ repetition cost. Frontiers in Psychology, 6.

Bak, T. H. (2015). Beyond a simple "yes" and "no". Cortex, 73, 332-333.

Barac, R., \& Bialystok, E. (2012). Bilingual effects on cognitive and linguistic development: Role of language, cultural background, and education. Child development, 83(2), 413-422.

Bialystok, E., Craik, F. I., Green, D. W., \& Gollan, T. H. (2009). Bilingual minds. Psychological Science in the Public Interest, 10(3), 89-129.

Branzi, F. M., Calabria, M., Boscarino, M. L., \& Costa, A. (2016). On the overlap between bilingual language control and domain-general executive control. Acta Psychologica, 166, 21-30.

de Bruin, A., Bak, T. H., \& Della Sala, S. (2015). Examining the effects of active versus inactive bilingualism on executive control in a carefully matched non-immigrant sample. Journal of Memory and Language, 85, 15-26.

von Bastian, C. C., Souza, A. S., \& Gade, M. (2016). No Evidence for Bilingual Cognitive Advantages: A Test of Four Hypotheses. Journal of Experimental Psychology: General, 145(2), 246-258. 
Calabria, M., Branzi, F. M., Marne, P., Hernández, M., \& Costa, A. (2015). Age-related effects over bilingual language control and executive control. Bilingualism: Language and Cognition, 18(1), 65-78.

Calabria, M., Hernández, M., Branzi, F. M., \& Costa, A. (2012). Qualitative differences between bilingual language control and executive control: Evidence from taskswitching. Frontiers in Psychology, 2.

Cattaneo, G., Calabria, M., Marne, P., Gironell, A., Abutalebi, J., \& Costa, A. (2015). The role of executive control in bilingual language production: A study with Parkinson's disease individuals. Neuropsychologia, 66, 99-110.

Cohen, J., \& Cohen, P. (1983). Applied multiple regression/correlation analysis for the behavioral sciences (2nd ed.). Hillsdale, NJ: Lawrence Erlbaum Associates.

Costa, A., Hernández, M., Costa-Faidella, J., \& Sebastián-Gallés, N. (2009). On the bilingual advantage in conflict processing: Now you see it, now you don't. Cognition, 113(2), 135-149.

Costa, A., Hernández, M., \& Sebastián-Gallés, N. (2008). Bilingualism aids conflict resolution: Evidence from the ANT task. Cognition, 106(1), 59-86.

Durkin, M., Prescott, L., Furchtgott, E., Cantor, J., \& Powell, D. A. (1995). Performance but not acquisition of skill learning is severely impaired in the elderly. Archives of Gerontology and Geriatrics, 20(2), 167-183.

Duñabeitia, J. A., Hernández, J. A., Antón, E., Macizo, P., Estévez, A., Fuentes, L. J., \& Carreiras, M. (2014). The inhibitory advantage in bilingual children revisited: Myth or reality? Experimental Psychology, 61(3), 234-251.

Gade, M., Schuch, S., Druey, M. D., \& Koch, I. (2014). Inhibitory control in task switching. In J. A. Grange, \& G. Houghton (Eds.), Executive Control and Task Switching. Oxford University Press. 
Garbin, G., Sanjuan, A., Forn, C., Bustamante, J. C., Rodriguez-Pujadas, A., Belloch, V., Hernández, M., Costa, A., \& Ávila, C. (2010). Bridging language and attention: brain basis of the impact of bilingualism on cognitive control. NeuroImage, 53(4), 1272-1278.

Gold, B. T., Kim, C., Johnson, N. F., Kryscio, R. J., \& Smith, C. D. (2013). Lifelong bilingualism maintains neural efficiency for cognitive control in aging. The Journal of Neuroscience, 33(2), 387-396.

Gobel, E. W., Blomeke, K., Zadikoff, C., Simuni, T., Weintraub, S., \& Reber, P. J. (2013). Implicit perceptual-motor skill learning in mild cognitive impairment and Parkinson's disease. Neuropsychology, 27(3), 314-321.

Hartanto, A., \& Yang, H. (2016). Disparate bilingual experiences modulate taskswitching advantages: A diffusion-model analysis of the effects of interactional context on switch costs. Cognition, 150, 10-19.

Hernández, M., Costa, A., \& Humphreys, G. W. (2012). Escaping capture: bilingualism modulates distraction from working memory. Cognition, 122(1), 37-50.

Hernández, M., Martin, C. D., Barceló, F., \& Costa, A. (2013). Where is the bilingual advantage in task-switching? Journal of Memory and Language, 69(3), 257-276.

Houtzager, N., Lowie, W., Sprenger, S., \& de Bot, K. (2015). A bilingual advantage in task switching? Age-related differences between German monolinguals and Dutch-Frisian bilinguals. Bilingualism: Language and Cognition, 1-11.

Kousaie, S., \& Phillips, N. A. (2012a). Conflict monitoring and resolution: Are two languages better than one? Evidence from reaction time and event-related brain potentials. Brain Research, 1446, 71-90. 
Kousaie, S., \& Phillips, N. A. (2012b). Ageing and bilingualism: Absence of a "bilingual advantage" in Stroop interference in a nonimmigrant sample. The Quarterly Journal of Experimental Psychology, 65(2), 356-369.

Kousaie, S., Sheppard, C., Lemieux, M., Monetta, L., \& Taler, V. (2014). Executive function and bilingualism in young and older adults. Frontiers in Behavioral Neuroscience, 8 .

Kroll, J. F., \& Bialystok, E. (2013). Understanding the consequences of bilingualism for language processing and cognition. Journal of Cognitive Psychology, 25(5), 497514.

Mayr, U., \& Keele, S. W. (2000). Changing internal constraints on action: the role of backward inhibition. Journal of Experimental Psychology: General, 129(1), 426.

Mor, B., Yitzhaki-Amsalem, S., \& Prior, A. (2015). The joint effect of bilingualism and ADHD on executive functions. Journal of Attention Disorders, 19(6), 527-541.

Paap, K. R., \& Greenberg, Z. I. (2013). There is no coherent evidence for a bilingual advantage in executive processing. Cognitive Psychology, 66(2), 232-258.

Paap, K. R., Johnson, H. A., \& Sawi, O. (2015). Bilingual advantages in executive functioning either do not exist or are restricted to very specific and undetermined circumstances. Cortex, 69, 265-278.

Paap, K. R., Johnson, H. A., \& Sawi, O. (2014). Are bilingual advantages dependent upon specific tasks or specific bilingual experiences? Journal of Cognitive Psychology, 26(6), 615-639.

Paap, K. R., \& Sawi, O. (2014). Bilingual advantages in executive functioning: problems in convergent validity, discriminant validity, and the identification of the theoretical constructs. Frontiers in Psychology, 5. 
Pelham, S. D., \& Abrams, L. (2014). Cognitive advantages and disadvantages in early and late bilinguals. Journal of Experimental Psychology: Learning, Memory, and Cognition, 40(2), 313-325.

Philipp, A. M., \& Koch, I. (2006). Task inhibition and task repetition in task switching. European Journal of Cognitive Psychology, 18(4), 624-639.

Prior, A. (2012). Too much of a good thing: Stronger bilingual inhibition leads to larger lag-2 task repetition costs. Cognition, 125(1), 1-12.

Prior, A., \& MacWhinney, B. (2010). A bilingual advantage in task switching. Bilingualism: Language and Cognition, 13(2), 253-262.

Prior, A., \& Gollan, T. H. (2011). Good Language-Switchers are Good Task-Switchers: Evidence from Spanish-English and Mandarin-English Bilinguals. Journal of the International Neuropsychological Society: JINS, 17(4), 682-691.

Prior, A., \& Gollan, T. H. (2013). The elusive link between language control and executive control: A case of limited transfer. Journal of Cognitive Psychology, 25(5), 622-645.

Raven, J., Raven, J. C., \& Court, J. H. (1998). Manual for Raven's advanced progressive matrices (1998 ed.). Oxford, England: Oxford Psychologists Press.

Rodrigue, K. M., Kennedy, K. M., \& Raz, N. (2005). Aging and longitudinal change in perceptual-motor skill acquisition in healthy adults. The Journals of Gerontology Series B: Psychological Sciences and Social Sciences, 60(4), 174-181.

Rodriguez-Fornells, A., Krämer, U. M., Lorenzo-Seva, U., Festman, J., \& Münte, T. F. (2012). Self-assessment of individual differences in language switching. Frontiers in Psychology, 2.

Schmidt, S. (2009). Shall we really do it again? The powerful concept of replication is neglected in the social sciences. Review of General Psychology, 13(2), 90-100. 
Stroebe, W., \& Strack, F. (2014). The alleged crisis and the illusion of exact replication. Perspectives on Psychological Science, 9(1), 59-71.

Valian, V. (2015). Bilingualism and cognition. Bilingualism: Language and Cognition, $18(01), 3-24$.

Vega-Mendoza, M., West, H., Sorace, A., \& Bak, T. H. (2015). The impact of late, nonbalanced bilingualism on cognitive performance. Cognition, 137, 40-46.

Verreyt, N., Woumans, E., Vandelanotte, D., Szmalec, A., \& Duyck, W. (2016). The influence of language-switching experience on the bilingual executive control advantage. Bilingualism: Language and Cognition, 19(01), 181-190.

Wiseheart, M., Viswanathan, M., \& Bialystok, E. (2016). Flexibility in task switching by monolinguals and bilinguals. Bilingualism: Language and Cognition, 19(01), 141-146.

Yang, H., Hartanto, A., \& Yang, S. (2016). The importance of bilingual experience in assessing bilingual advantages in executive functions. Cortex, 75, 237-240. 


\section{Footnotes}

${ }^{1}$ It is important to distinguish between direct (or exact) and conceptual replications in experimental science (see Schmidt, 2009). In direct replication, the same task, type of participants, method, procedures and analysis are used to establish if seminal findings can be replicated. Conceptual replication refers to the use of a conceptually similar experimental setting (not exactly the same) to measure the same theoretical variables. Conceptual replications are crucial in experimental science since they allow investigating the extent to which research findings can be generalised beyond the experiment itself (Stroebe \& Strack, 2014).

${ }^{2}$ Note that task inhibition (measured through the $\mathrm{n}-2$ repetition cost) is a rather fundamental mechanism in the sense that it is also observable in preplanned sequences (Mayr \& Keele, 2000). In other words, even if participants know that they must switch back to a previously performed task, they experience the $n-2$ repetition cost. Hence, the higher n-2 repetition cost for bilinguals vs. monolinguals (Prior, 2012) could reflect a negative effect of bilingual language control on a very automatic EC process.

${ }^{3}$ Kroll and Bialystok (2013) proposed a similar hypothesis - bilingualism would confer a general greater efficiency of EC functioning.

${ }^{4}$ In some studies, bilingual and monolingual participants were matched according to their basic perceptual-motor skills (e.g., Paap et al., 2013) and video-game experience (e.g., Costa et al., 2009) to avoid confounding. In the present study, such information could not be provided. Although this missing data represented a shortcoming, at least, the compared groups were homogeneous regarding variables (age and health conditions) that have been known to affect basic perceptual-motor skills (see Durkin, Prescott, Furchtgott, Cantor \& Powell, 1995; Rodrigue, Kennedy \& Raz, 2005; Gobel, Blomeke, Zadikoff, Simuni, Weintraub \& Reber, 2013). 
${ }^{5}$ Similar to Experiment 1, in this experiment, bilinguals and monolinguals were also not matched based on their basic perceptual-motor skills and video-game experience.

${ }^{6}$ Note that the "reduction" in the number of repetitions in the task refers to the overall number of repetition trials (i.e., CAA trials) presented in the task compared to the other types of trials (i.e., CBA and ABA trials).

${ }^{7}$ We performed one repeated-measures ANOVA with types of cost $(\mathrm{n}-2$ repetition and $\mathrm{n}$ 1 shift costs) as a within-subject factor and group (bilinguals and monolinguals) as a between-subject factor. The main effect of types of cost was not significant $[\mathrm{F}(1,181)=$ 1.844, $\left.p=0.176, \eta p^{2}=0.010\right]$, suggesting that the magnitudes of the $n-1$ shift cost and of the $\mathrm{n}-2$ repetition cost were not different. The main effect of group was not significant, either $\left[F(1,181)=0.186, p=0.666, \eta p^{2}=0.001\right]$, suggesting that the two groups performed similarly. Finally, the interaction between types of cost and group was also not significant $\left[\mathrm{F}(1,181)=1.074, p=0.301, \eta \mathrm{p}^{2}=0.006\right]$. 
Table 1. Information on languages and self-assessed proficiency of bilinguals and monolinguals: Experiment 1.

L1 L2 L3

\begin{tabular}{lccc}
\hline \hline BILINGUALS & & & \\
\hline $\begin{array}{l}\text { Age of Acquisition } \\
\text { Context of language exposure }\end{array}$ & $\begin{array}{c}0.5(0.5) \\
\text { home, school }\end{array}$ & $\begin{array}{c}1.5(1.6) \\
\text { home, school }\end{array}$ & $7(3.4)$ \\
Reading & $7(0.5)$ & $7(0.4)$ & $5(0.9)$ \\
Writing & $7(0.5)$ & $7(0.5)$ & $5(0.9)$ \\
Speaking & $7(0.4)$ & $7(0.5)$ & $5(1.2)$ \\
Comprehension & $7(0.3)$ & $7(0.3)$ & $5(1.2)$ \\
& & & \\
\hline \hline
\end{tabular}

\begin{tabular}{lccl}
\hline \hline MONOLINGUALS & & & \\
\hline Age of Acquisition & $1(0.7)$ & $6(2.1)$ & - \\
$\begin{array}{l}\text { Context of language exposure } \\
\text { Language proficiency }\end{array}$ & some, school & & - \\
Reading & $7(0.4)$ & $5(1.3)$ & - \\
Writing & $7(0.6)$ & $4(1.2)$ & - \\
Speaking & $7(0.5)$ & $4(1.6)$ & - \\
Comprehension & $7(0.6)$ & $4(1.3)$ & -
\end{tabular}

Language proficiency scores were measured on a 7-point scale, where $7=$ a very high level and $1=$ a very low level of proficiency. The self-

assessed index is the average (mean) of participants' responses relative to each domain (reading, writing, speaking and comprehension). The SDs are enclosed in parentheses. 
Table 2. Mean RTs, error rates and magnitude of the $n$-2 repetition cost in the two groups (bilinguals and monolinguals): Experiment 1.

\begin{tabular}{|c|c|c|c|}
\hline & Bilinguals & Monolinguals & Bil-Mono \\
\hline \multicolumn{4}{|l|}{$R T s$} \\
\hline$C B A$ & 1037 (43) & $1186(40)$ & -149 \\
\hline$A B A$ & $1087(45)$ & $1248(41)$ & -161 \\
\hline TOT RTs & $1062(44)$ & $1217(41)$ & -155 \\
\hline$n-2$ repetition cost & $50(7)$ & $62(7)$ & -12 \\
\hline \multicolumn{4}{|l|}{ Error rates } \\
\hline$C B A$ & $3.4 \%(0.4)$ & $2.8 \%(0.3)$ & $0.6 \%$ \\
\hline$A B A$ & $3.3 \%(0.4)$ & $3.3 \%(0.3)$ & $0.0 \%$ \\
\hline TOT Error rates & $3.4 \%(0.4)$ & $3.0 \%(0.3)$ & $0.4 \%$ \\
\hline$n-2$ repetition cost & $-0.1 \%(0.2)$ & $0.5 \%(0.2)$ & $-0.6 \%$ \\
\hline
\end{tabular}

The standard errors (SEs) are enclosed in parentheses. 
Table 3. Information on languages and self-assessed proficiency of bilinguals and monolinguals: Experiment 2.

$\mathbf{L 1} \mathbf{L 2} \mathbf{L 3}$

\begin{tabular}{lccc}
\hline \hline BILINGUALS & & \\
\hline $\begin{array}{l}\text { Age of Acquisition } \\
\text { Context of language exposure }\end{array}$ & $\begin{array}{c}\text { 0.5 }(0.1) \\
\text { home, school }\end{array}$ & $\begin{array}{c}1.4(1.8) \\
\text { home, school }\end{array}$ & $\begin{array}{c}\text { Lange }(3.3) \\
\text { school }\end{array}$ \\
Reading & $7(0.4)$ & $7(0.4)$ & $5(1.0)$ \\
Writing & $7(0.7)$ & $6(0.7)$ & $5(1.1)$ \\
Speaking & $7(0.5)$ & $7(0.6)$ & $4(1.2)$ \\
Comprehension & $7(0.3)$ & $7(0.3)$ & $5(1.2)$ \\
\hline \hline
\end{tabular}

\begin{tabular}{lccl}
\hline \hline MONOLINGUALS & & $7(2.5)$ & - \\
\hline Age of Acquisition & $1(1)$ & school & - \\
Context of language exposure & home, school & & - \\
Language proficiency & & $4(1.3)$ & - \\
Reading & $7(0.3)$ & $4(1.4)$ & - \\
Writing & $7(0.5)$ & $4(1.6)$ & - \\
Speaking & $7(0.5)$ & $4(1.5)$ & - \\
Comprehension & $7(0.4)$ & &
\end{tabular}

Language proficiency scores were measured on a 7-point scale, where $7=$ a very high level and $1=$ a very low level of proficiency. The selfassessed index is the average of participants' responses relative to each domain (reading, writing, speaking and comprehension). The SDs are enclosed in parentheses. 
Table 4. Mean RTs, error rates and magnitude of the $\boldsymbol{n}$ - 2 repetition cost and $\boldsymbol{n}$ - 1 shift cost in the two groups (bilinguals and monolinguals): Experiment 2.

\begin{tabular}{|c|c|c|c|}
\hline & Bilinguals & Monolinguals & Bil-Mono \\
\hline \multicolumn{4}{|l|}{$R T s$} \\
\hline$\overline{C A A}$ & $987(18)$ & $1023(17)$ & -36 \\
\hline$C B A$ & $1037(21)$ & $1066(20)$ & -29 \\
\hline$A B A$ & $1080(21)$ & $1122(20)$ & -42 \\
\hline TOT RTs & $1035(20)$ & $1070(19)$ & -35 \\
\hline$n-2$ repetition cost & $43(5)$ & $56(5)$ & -13 \\
\hline$n-1$ shift cost & $50(10)$ & $43(9)$ & 7 \\
\hline \multicolumn{4}{|l|}{ Error rates } \\
\hline$\overline{C A A}$ & $2.5 \%(0.3)$ & $3.2 \%(0.3)$ & $-0.7 \%$ \\
\hline$C B A$ & $3.2 \%(0.2)$ & $3.2 \%(0.2)$ & $0.0 \%$ \\
\hline$A B A$ & $3.4 \%(0.3)$ & $3.8 \%(0.2)$ & $-0.4 \%$ \\
\hline TOT Error rates & $3.0 \%(0.2)$ & $3.4 \%(0.2)$ & $-0.4 \%$ \\
\hline$n-2$ repetition cost & $0.2 \%(0.2)$ & $0.6 \%(0.2)$ & $-0.4 \%$ \\
\hline$n-1$ shift cost & $0.7 \%(0.3)$ & $0 \%(0.2)$ & $0.7 \%$ \\
\hline
\end{tabular}

The SEs are enclosed in parentheses. 
Table 5. BSWQ in Experiments 1 and 2.

\begin{tabular}{lcc}
\hline \hline & Experiment 1 & Experiment 2 \\
\hline BSWQ & & \\
\hline L1S & $9(2)$ & $9(2)$ \\
L2S & $8(2)$ & $8(2)$ \\
S & $9(2)$ & $8(2)$ \\
$\boldsymbol{U S}$ & $6(3)$ & $7(2)$ \\
OS & $32(6)$ & $32(6)$
\end{tabular}

Mean raw scores for L1-switching tendencies (L1S), L2-switching tendencies (L2S), contextual switch (CS), unintended switch (US) and overall switch (OS). The SDs are enclosed in parentheses. 
Table 6. Correlation between BSWQ scores and switch costs in Experiments 1 and 2.

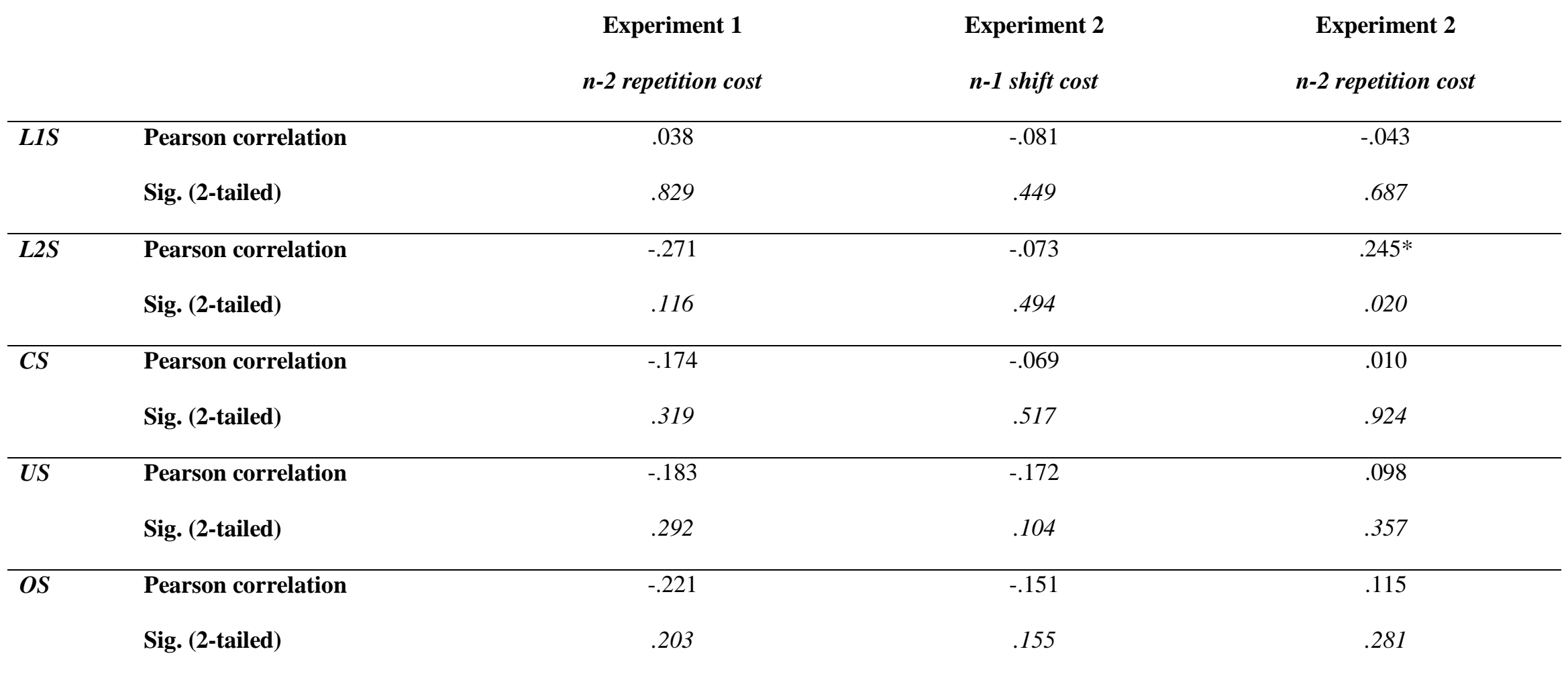

** Correlation is significant at the .01 level (2-tailed).

* Correlation is significant at the .05 level (2-tailed).

Results from the correlation analyses between BSWQ mean scores and magnitudes of the switch costs ( $\mathrm{n}-1$ shift cost and n-2 repetition cost 


\section{FIGURE CAPTIONS:}

Figure.1. Experiment 2. Correlation between the n-2 repetition costs and the n-1 shift costs for bilinguals and monolinguals.

Figure.2. Experiment 2. Correlation between the n-2 repetition costs and the n-1 shift costs for bilinguals.

Figure.3. Experiment 2. Correlation between the n-2 repetition costs and the n-1 shift costs for monolinguals. 
Figure 1.

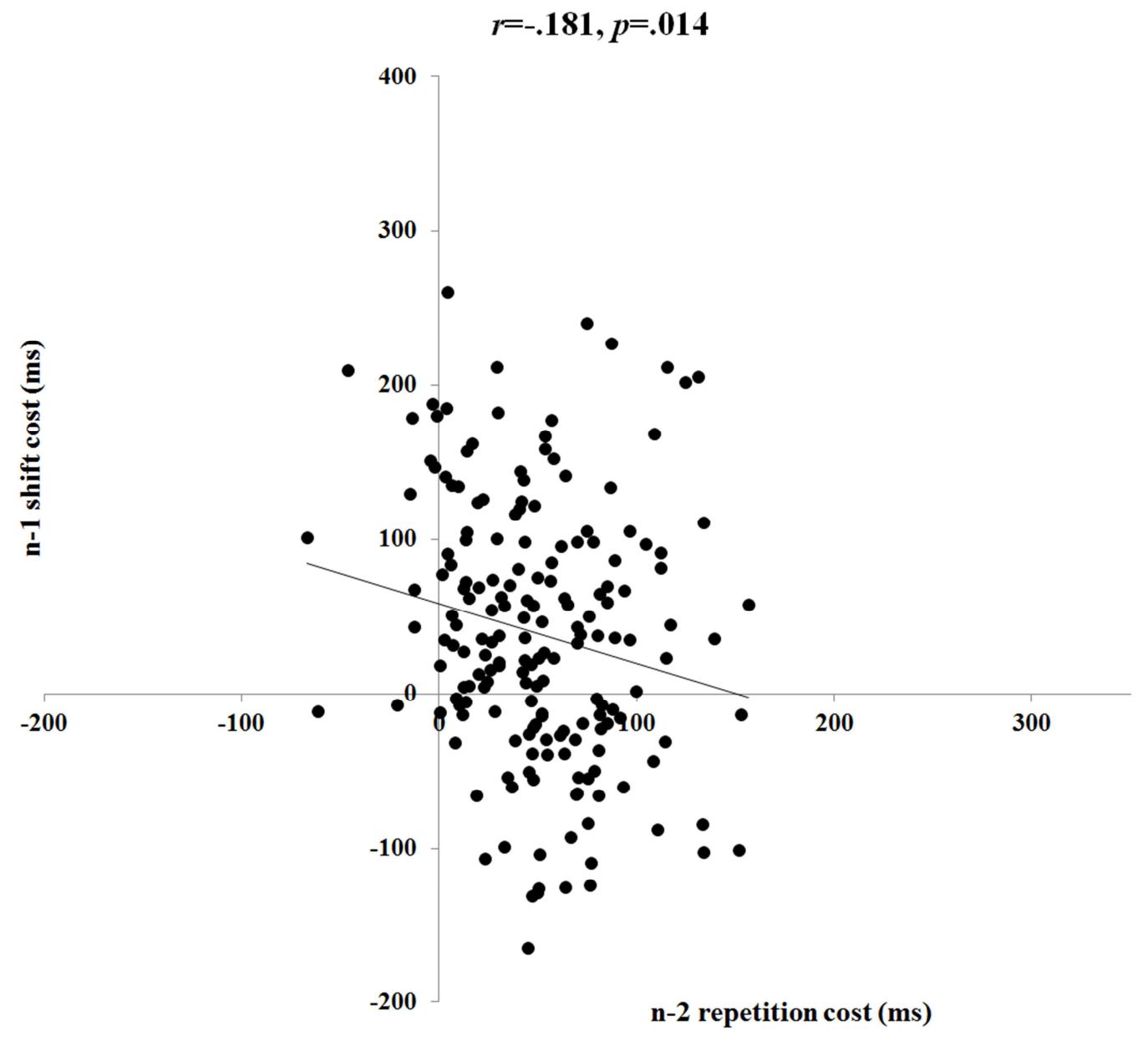


Figure 2.

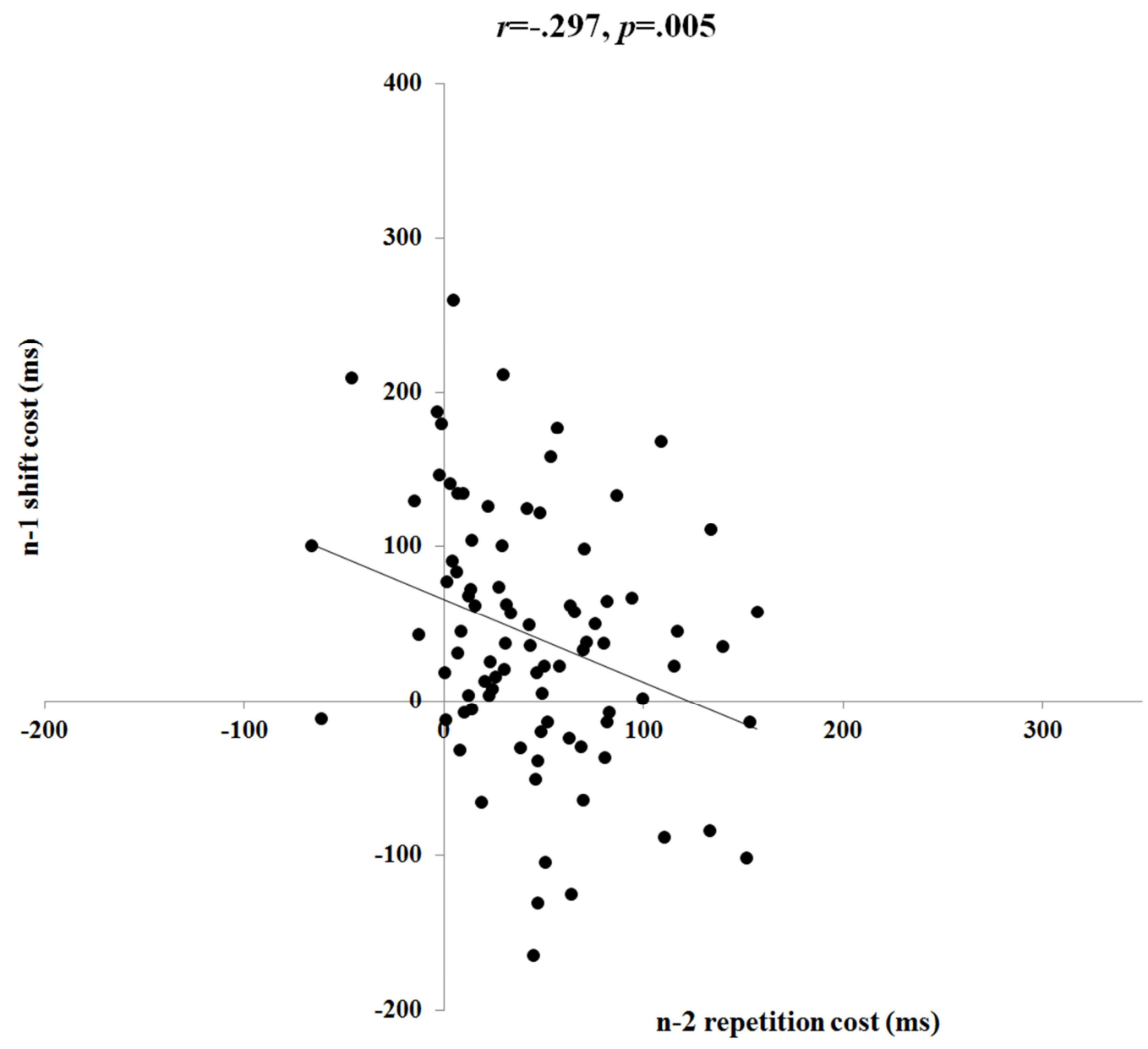


Figure 3.

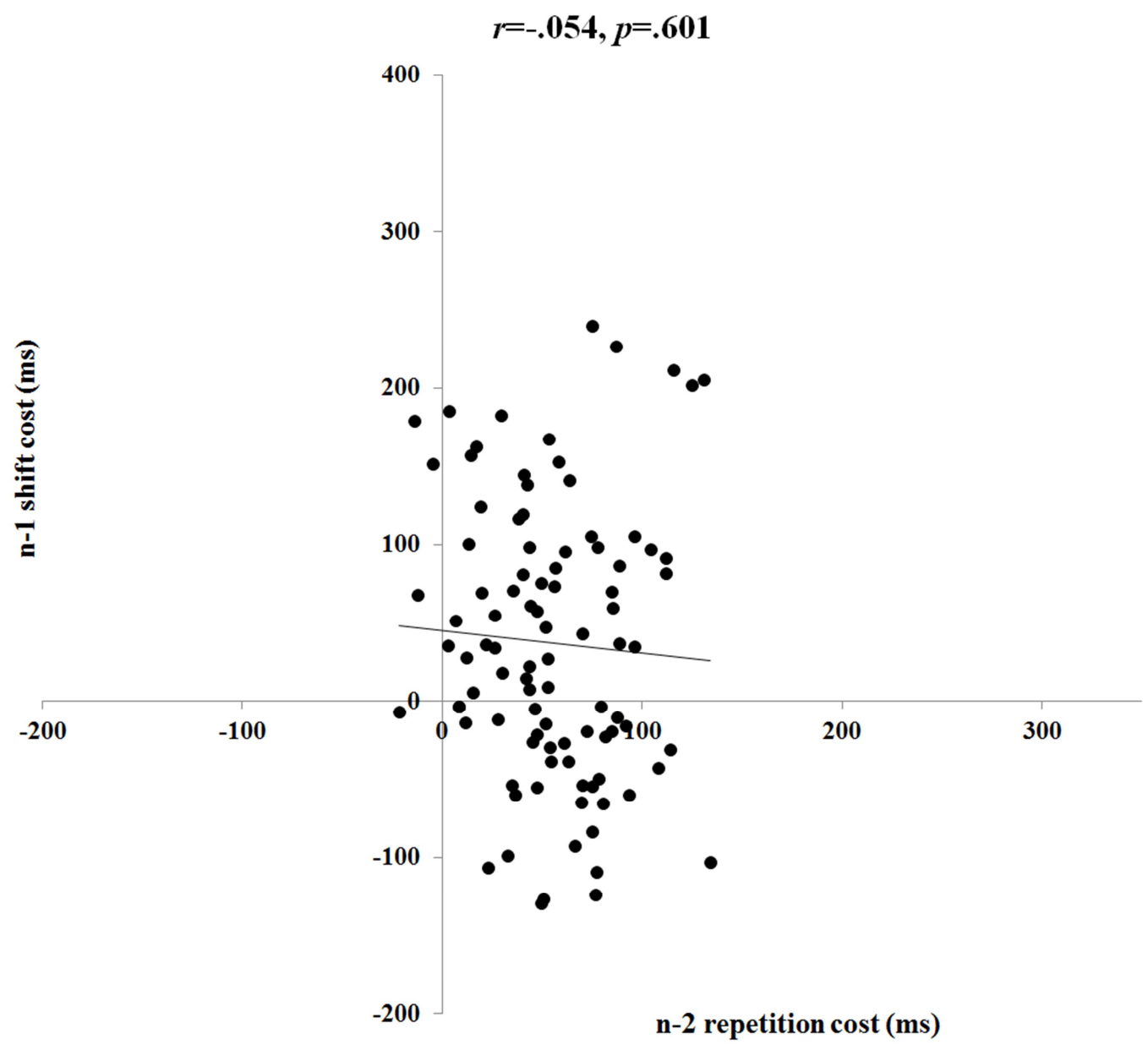




\section{Appendix}

\section{Description of monolingual and bilingual samples}

All participants (both bilinguals and monolinguals) who were recruited for the two experiments lived in the same country (Spain). Hence, despite their exposure to the same socio-cultural context, they differed in their language history. The monolinguals who were included in both experiments were students at the University of Murcia. The bilinguals in both experiments were Catalan-Spanish early and highly proficient bilinguals and were students at the Pompeu Fabra University.

\section{Catalan-Spanish bilinguals}

The Catalan-Spanish bilinguals who participated in Experiments 1 and 2 were recruited in Catalonia, specifically in Barcelona. Catalonia is a bilingual region in Spain, where both Catalan and Spanish are official languages. In many families, both languages are spoken, and the current educational system is completely bilingual. At the end of primary school, children are able to read, write, speak and understand both Catalan and Spanish. In primary school and in high school, classes are taught in both languages although Catalan is more predominant. University classes and tests are taught and administered in both Catalan and Spanish. Radio and television broadcasts are aired in both languages, newspaper articles are written in Catalan and Spanish, and the official bureaucracy can be handled in either language. All the Catalan-Spanish bilinguals who were tested in the experiments passed the Catalan-Spanish language proficiency exam that is required for admission to universities. This exam requires a very high level of proficiency in various aspects (grammar, vocabulary, etc.). In Barcelona, CatalanSpanish conversations are prevalent in both private and professional settings. This 
promotes a balanced use of the two languages, as well as situations in which (even if not needed) language switching in bilingual groups occurs naturally.

For example, it is common to observe that an interlocutor speaks in Spanish to a particular person and in Catalan to another during the same conversation, even if all three speakers are highly proficient bilinguals (even among members of the same family).

All the Catalan-Spanish bilinguals who were tested in this study were exposed early (before the age of two years) to both languages in similar proportions, and they kept using these in this way until the time of testing.

The bilinguals were asked to rate their proficiency skills in reading, writing, speaking and comprehension in their two native languages, as well as in any foreign language in which they were better at (see Tables 1 and 3 ).

\section{Spanish monolinguals}

The Spanish monolinguals who participated in Experiments 1 and 2 were recruited in the Region of Murcia (autonomous community), especially in Murcia, a monolingual city in Spain. These monolingual participants were not functionally fluent in any other language despite formal foreign language instruction in school (see also Prior \& MacWhinney, 2010; Prior, 2012; Hernandez et al., 2013).

Importantly, no monolingual reported currently using or having used in the past any language other than Spanish with relatives (including parents and siblings), partners, friends or in an educational or work setting. In fact, as shown in Tables $\mathbf{1}$ and $\mathbf{3}$, the monolinguals did not report a high level of proficiency in a foreign language. They were asked to rate their proficiency skills in reading, writing, speaking and comprehension in 
their native language, as well as in any foreign language they were better at (see Tables 1 and 3). 